\title{
Steam Oxidation of Aluminide Coatings under High Pressure and for Long Exposures
}

\author{
Claire Boulesteix $^{1}$, Vladislav Kolarik ${ }^{2}$, Fernando Pedraza ${ }^{1}$ \\ ${ }^{1}$ Laboratoire des Sciences de l'Ingénieur pour l'Environnement (LaSIE, UMR-CNRS 7356), \\ Université de La Rochelle, Avenue Michel Crépeau, 17042 La Rochelle Cedex 1, France \\ ${ }^{2}$ Fraunhofer-Institut für Chemische Technologie, Joseph-von-Fraunhofer Str. 7, Pfinztal \\ 76327, Germany \\ Corresponding authors: claire.boulesteix@univ-lr.fr;fernando.pedraza@univ-lr.fr
}

\begin{abstract}
B2-FeAl-based aluminide coatings were elaborated on P92 ferritic-martensitic steels by slurry. Under atmospheric pressure of steal and $650^{\circ} \mathrm{C}$, a thin protective $\alpha-\mathrm{Al}_{2} \mathrm{O}_{3}$ oxide layer formed and was maintained until $5000 \mathrm{~h}$. With increasing pressure to $300 \mathrm{bar}$, the morphology of $\alpha-\mathrm{Al}_{2} \mathrm{O}_{3}$ changed markedly. Iron oxide clusters started to appear at the surface of the scale after $5000 \mathrm{~h}$ of exposure and kept on growing till $10000 \mathrm{~h}$. It appears that pressure increased the outward diffusion of Fe through the coating and through the oxide scale and fostered the propagation of the tensile cracks of the coating.
\end{abstract}

Keywords: Ferritic-martensitic steels, Aluminium diffusion coatings, Oxidation, Steam, Pressure.

\section{INTRODUCTION}

Greater temperatures and pressures allow significant increases of efficiency in steam power plants $[1,2]$. These improvements require metallic materials with adequate mechanical and oxidation resistances [2-5]. In this case, heat resistant ferritic-martensitic steels are commonly used for superheater tubes and pipes in ultrasupercritical boilers [6,7]. They offer a better heat transfer behaviour and lower thermal expansion coefficients $[6,8,9]$ than austenitic stainless steels or the more expensive nickel base alloys Among this steel range, the T/P92 heat resistant steels (ASME grade 92) have been recognized as key structural components for ultrasupercritical power plants [10]. Despite its good properties, the P92 ferritic-martensitic steel has to be employed up to $650^{\circ} \mathrm{C}$ to maintain its mechanical resistance [6].

The behaviour of this material has been studied in steam environments under different pressures [11, 12]. Agüero et al. have shown that after $3000 \mathrm{~h}$ under atmospheric pressure and in pure steam, an oxide scale of about $180 \mu \mathrm{m}$ thick, composed by two major layers constituted 
by magnetite, was formed. Additional $(\mathrm{Fe}, \mathrm{Cr})_{3} \mathrm{O}_{4}$ spinels were found in the inner part of the oxide layer [11]. Similar results were reported by Boulesteix et al. after $2000 \mathrm{~h}$ of exposure in steam and under 1 bar [12]. Ehlers et al. found an additional thin outer layer of hematite in water vapour containing atmospheres [13]. By increasing the pressure to $180 \mathrm{bar}$, the oxide formed in steam was thicker but displayed the same layered structure and oxide phases. In contrast, a higher degree of porosity and delamination from the substrate were observed [11]. Yin et al. have conducted experiments in supercritical water for several hundred $\mathrm{h}$ at $600^{\circ} \mathrm{C}$ and under 250 bar. Again, a bilayered oxide structure was reported. By increasing the pressure, it seems that the porosity increased but by increasing the exposure time, this phenomenon tends to stabilize [14]. Moreover, Zhu et al. have tested the P92 ferritic-martensitic steel in deaerated supercritical water under the same pressure but at $650^{\circ} \mathrm{C}$ which corresponds to the maximal operating temperature of this alloy. The magnetite/spinel-mixed structure was non adherent and internal oxidation phenomenon of the substrate was noticed [14]. Furthermore, above $600^{\circ} \mathrm{C}$, evaporation of volatile $\mathrm{CrO}_{2}(\mathrm{OH})_{2}$ species became significant and the breakdown of the oxide layer formed occurred $[6,15]$. In all cases, the oxide scale formed is non protective and in power plants, in view of the significant oxide thicknesses encountered, it could cause the clogging of the boiler tubes and their subsequent burst.

Therefore, the elaboration of a protective coating appears to be necessary and, as it happens, the slurry aluminium coating is a promising way. Indeed, this technique is a low cost and easy-to-apply process which allows to coat large components irrespective of its shape. The slurry developed in our research group is "environmentally friendly" because water is used as a solvent [16]. The mechanisms of formation of these coatings on austenitic and ferriticmartensitic steels have been largely described in [17-20]. The good behaviour of these coatings in air, argon or steam at intermediate temperatures $\left(650<\mathrm{T}<700^{\circ} \mathrm{C}\right)$ has been demonstrated by previous works conducted in our group $[12,19,21]$. As it happens, it was shown the steam oxidation resistance of ferritic-martensitic and ofr austenitic stainless steels was greatly improved at respectively, $650^{\circ} \mathrm{C}$ and $700^{\circ} \mathrm{C}$ and under 1 bar when the materials were coated with a slurry aluminium coating in spite of the presence of tensile cracks. Indeed, the formation of a thin oxide layer exclusively composed by $\alpha-\mathrm{Al}_{2} \mathrm{O}_{3}$ ensured the protection of the tested materials even after thousands of $\mathrm{h}[11,12,21,22]$. However, by increasing the pressure, the degradation of the coating becomes faster and it appears that the scales formed are thicker [11]. Based on these observations, it is difficult to ascertain whether the detrimental effect derives from cyclic conditions in the plant or from the pressure itself. 
Thus, this paper investigates the effect of pressure (1 vs. 300 bar) on a slurry aluminised P92 steel exposed to steam, at $650^{\circ} \mathrm{C}$, for $5000 \mathrm{~h}$. A second part of the paper shows the evolution of the slurry aluminised P92 steel exposed to 300 bar till $10000 \mathrm{~h}$.

\section{EXPERIMENTAL PROCEDURE}

\subsection{Steel substrate}

P92 coupons (20x10x2 mm) were ground with SiC \#180 paper, grit blasted with a 220 mesh $\mathrm{Al}_{2} \mathrm{O}_{3}$ particles, then rinsed in deionised water and finally cleaned with ethyl alcohol under ultrasonic agitation before drying with hot air. The compositions (nominal and determined by Energy Dispersive Spectroscopy (EDS) analysis) of this alloy are given in Table 1.

TABLE 1. Nominal and experimental (EDS) compositions of P92 (at\%).

\begin{tabular}{|c|c|c|c|c|c|c|}
\hline \multicolumn{7}{|c|}{ P92 ferritic-martensitic steel } \\
\hline Composition (at\%) & Fe & Cr & C & W & Si & Others \\
\hline \multirow{2}{*}{ Nominal } & \multirow{2}{*}{ Bal } & $9.2-10.3$ & $0.03-0.06$ & $0.5-0.6$ & $<1$ & Mn: $0.3-0.6$ \\
& & & & & & Ni: $<0.4$ \\
& & & & & & V: $0.15-0.4$ \\
\hline \multirow{2}{*}{ EDS } & 87 & 10 & - & 0.6 & 0.8 & Mn: 0.6 \\
& & & & & & Vo, Ni: $<0.4$ \\
& & & & & \\
\hline
\end{tabular}

\subsection{Aluminisation}

The aluminium micro-particles employed to elaborate the slurry were the same used in our previous works $[12,19,20,21,23]$ (4-5 $\mu \mathrm{m}$ average size, Hermillon, France). The P92 samples were coated by spraying a slurry containing $43 \mathrm{wt} \% \mathrm{Al}$ microparticles dispersed in $57 \mathrm{wt} \%$ of binder (1/10 polyvynil alcohol/deionized water). After drying in ambient air for at least 1 hour [16], the coated samples were annealed in $\operatorname{argon}\left(400^{\circ} \mathrm{C} / 3 \mathrm{~h}+650^{\circ} \mathrm{C} / 3 \mathrm{~h}+1050^{\circ} \mathrm{C} / 1 \mathrm{~h}\right)[20]$. The $\mathrm{O}_{2}$ partial pressure in the furnace where the thermal treatment takes place is lower than $10^{-6}$ mbar and by referring to the Ellingham diagram [24], it appears that $\mathrm{Al}_{2} \mathrm{O}_{3}$ can be formed. It was shown that in these conditions, $\alpha-\mathrm{Al}_{2} \mathrm{O}_{3}$ was formed after annealing of the aluminised samples $[17,25]$. Once the thermal treatment done, the samples were grit blasted with a 220 
mesh $\mathrm{Al}_{2} \mathrm{O}_{3}$ in order to eliminate the residual empty microparticles on the coated material ("bisque"). Nevertheless, the coating appeared preoxidised after the annealing [F. Pedraza, M. Mollard, B. Rannou, J. Balmain, B. Bouchaud, G. Bonnet, Mater. Chem. Phys. 134 (2012), 700-705].

\subsection{Steam tests}

The isothermal oxidation tests were carried out at $650^{\circ} \mathrm{C}$ and under 1 bar. For these experiments, the aluminised $\mathrm{P} 92$ samples were introduced in a tubular furnace and heated at $20^{\circ} \mathrm{C} / \mathrm{min}$ until $650^{\circ} \mathrm{C}$ and were subsequently maintained for $5000 \mathrm{~h}$ with a constant steam flow $\left(7 \mathrm{x} 10^{-2} \mathrm{~m} . \mathrm{s}^{-}\right.$

$\left.{ }^{1}\right)$. The steam was produced from deionized water using silica filtered and content of $\mathrm{O}_{2}$ dissolved was lower than $0.05 \mathrm{mg} . \mathrm{L}^{-1}$.

The high pressure tests were conducted at the Fraunhofer Institut, Pfinztal (Germany). Laboratory tests autoclaves from Alloy 602 were closed by welding, inserted into a muffle furnace and connected to the pressured gas supply system. The samples were oxidised for up to $10000 \mathrm{~h}$ at $650^{\circ} \mathrm{C}$ under a pressure of 300 bar [26].

\subsection{Characterisation of the samples}

Before and after oxidation, the crystal structures of the samples were determined by X-Ray Diffraction (XRD) using a Bruker AXS D8 Advance ( $\mathrm{CuK}_{\alpha}$ radiation), in $\theta-2 \theta$ mode. Morevoer, the surfaces and the cross-sections of the aluminised P92 samples were characterised by scanning-electron microscopy (SEM) coupled to energy-dispersive spectrometry (EDS) using a FEI Quanta 200F Field Emission Gun Scanning Electron Microscope (FEG-SEM) at $20 \mathrm{kV}$ with an EDAX detector operating under low vacuum. In order to observe the spatial distribution of the elements in a wider area and to observe the oxide layers formed, X-ray maps were realized after oxidation tests. The cross-sections of the oxidised samples were also observed using a Leica DMRM microscope and a LEICA MC170HD camera coupled with the software LAS v4.9 for the images acquisition. Raman microspectrometry analyses were also performed with a Horiba Jobin Yvon LabRam HR apparatus using a He-Ne laser $(632.8 \mathrm{~nm})$ in order to obtain more information about the oxide layers. The analyses were performed every $500 \mu \mathrm{m}$ from the centre to the edges to map the likely evolutions in composition at local scale.

\section{RESULTS}


XRD characterisations were performed on the raw P92 steel, on the "as-sprayed" coating (before aluminisation) and after the thermal treatment allowing the formation of the aluminide coating. As shown in Fig. 1, the six characteristic peaks of the B2-FeAl phase were detected (JCPDS 00-033-0020) on the aluminised P92 steel. The blue diffractogram which shows the "as-sprayed" specimen let appeared one peak with a lower intensity $\left(2 \theta \approx 37^{\circ}\right)$ which can be attributed to the $\mathrm{Al}$ oxyhydroxides contained in the slurry [16].

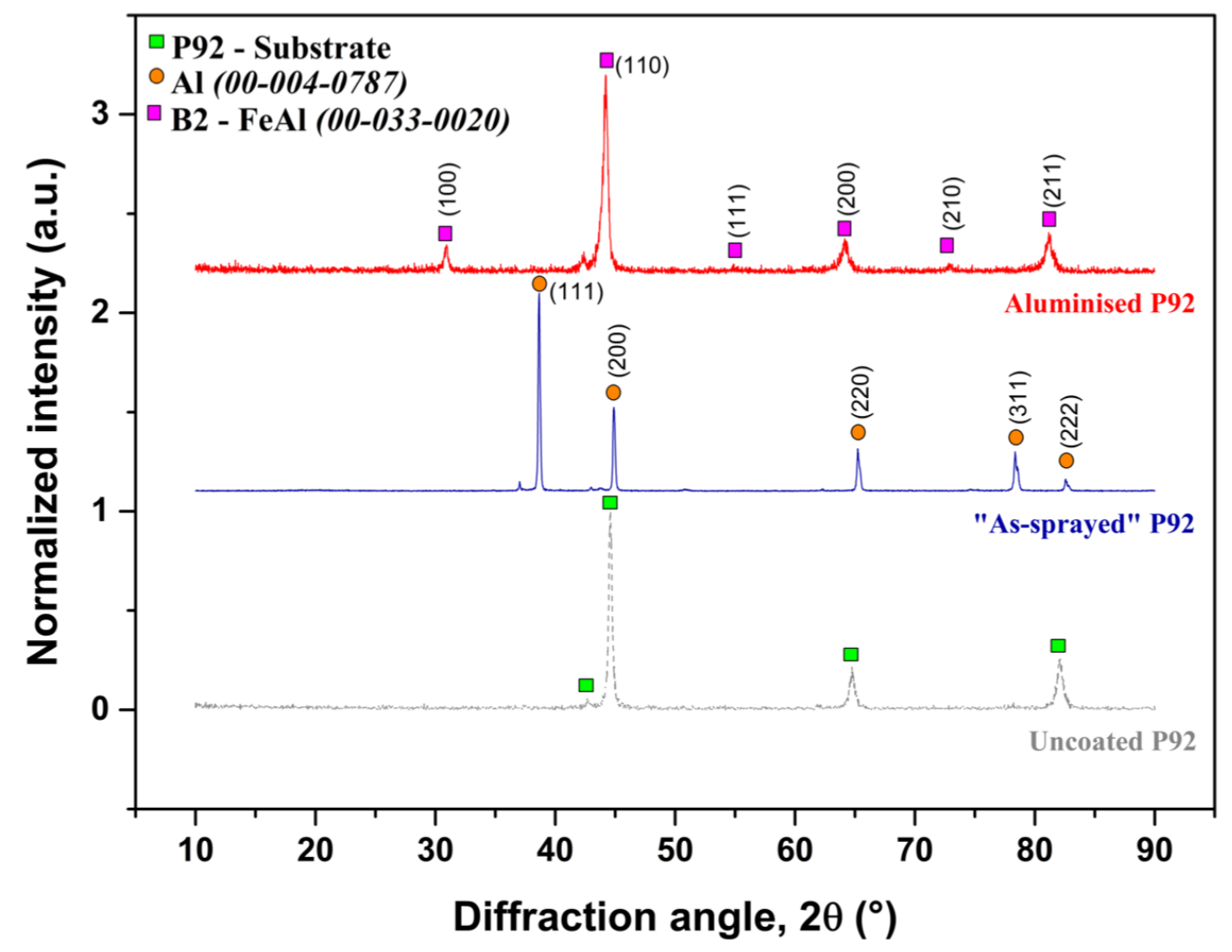

FIGURE 1. X-ray patterns of the P92 ferritic-martensitic steel before and after aluminisation.

Figs. 2. a. and b. show the micrographs obtained on the surface of the aluminised samples and on the corresponding cross section. The EDS analyses performed on the latter are also shown (Fig. 2. c.). The surface of the sample appeared to be rough because of the final step consists of a light grit blasting (Fig. 2. a.). As previously seen in [20, 27], the coating elaborated on the P92 ferritic-martensitic steel can be divided in two parts. The first part corresponded to the diffusion zone (or additive layer) and was about $60 \mu \mathrm{m}$ thick. The EDS analyses (Fig. 2. c.) performed on this outer layer confirmed the XRD findings (Fig. 1). Indeed, by referring to the Fe-Al binary diagram [28], with 40 at $\% \mathrm{Al}+54$ at $\% \mathrm{Fe}$ at the top of the coating and $25 \mathrm{at} \% \mathrm{Al}$ $+68 \mathrm{at} \% \mathrm{Fe}$ at the interface between the additive layer and the interdiffusion zone, the major phase contained in the diffusion zone corresponded to B2-FeAl. The inner part of the coating 
(the interdiffusion zone) was similar in terms of thickness (67 $\mu \mathrm{m}$ thick) but was less homogenous compared to the first one. Needle-like precipitates were observed and were attributed to $\mathrm{Al}$ nitrides, due to the presence of $\mathrm{N}$ in the substrate, as previously reported in [20, 29, 30]. Moreover, the diffusion coefficients of $\mathrm{Al}$ and of the compounds of the substrate were different, a Kirkendall effect was induced involving some porosities in the coating [20]. Cracks were also observed and were correlated to the mismatch of the thermal expansion coefficient existing between the different metallurgical phases $[11,20,20,30]$.
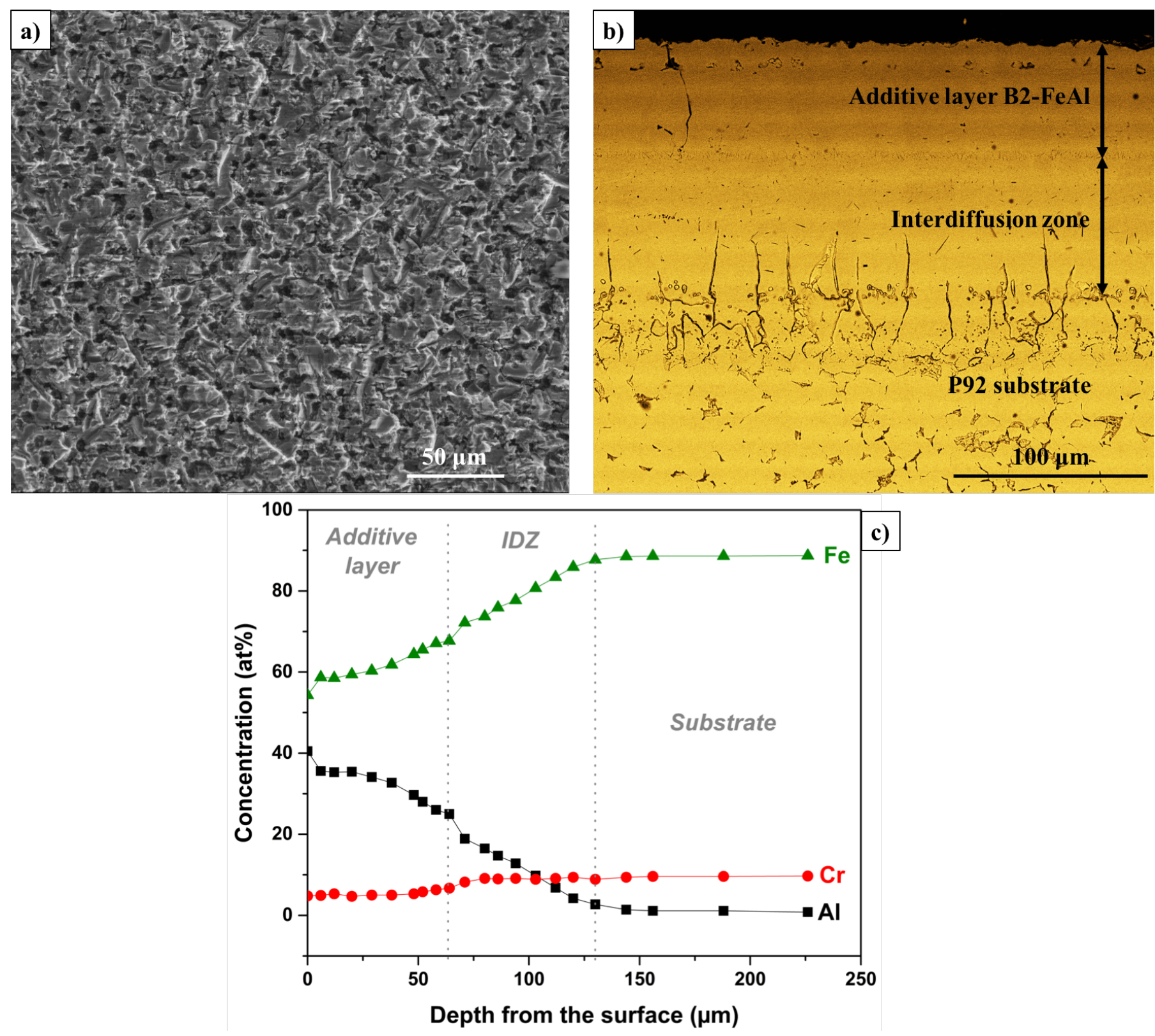

FIGURE 2. SEM (a) surface and (b) cross section of and aluminised P92 specimen. (c) Corresponding EDS profiles. 
The aluminised P92 ferritic-martensitic steels were exposed for $5000 \mathrm{~h}$ at $650^{\circ} \mathrm{C}$ in steam and under 1 or 300 bar of pressure.

The surface of the tested steel after $5000 \mathrm{~h}$ of exposure under atmospheric pressure (Fig. 3. a.) appeared similar compared to those obtained after aluminisation and grit blasting (Fig. 2. a.). Indeed, the roughness of the sample was still observable and cracks were detected on its surface but they appeared self-healed as highlighted in the Xray maps shown in Fig. 4. At higher magnification (Fig. 3. b.), whiskers covering the entire oxidised surface were observed.
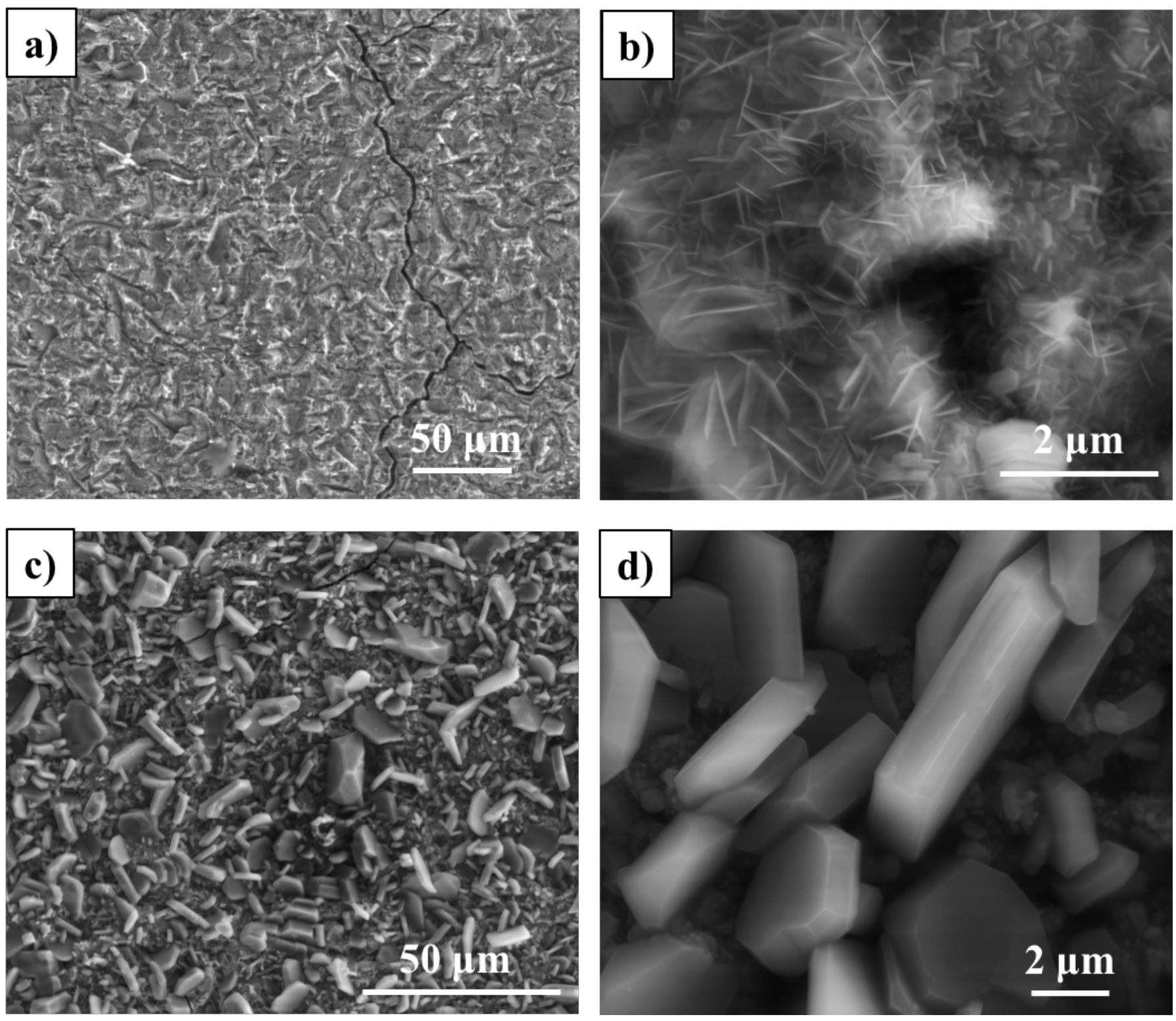

FIGURE 3. Surfaces of the aluminised P92 ferritic-martensitic steel exposed for 5000 hours in steam, at $650^{\circ} \mathrm{C}$ and under (a, b) atmospheric pressure and under (c, d) 300 bar. 
As shown in Fig. 4, in some parts of the coating, the cracks propagated beyond the additive layer/interdiffusion zone interface. However, aluminium and oxygen have been detected into them, as well as on the surface. Indeed, a very thin scale can be observed on the samples and can be compared to the results obtained in [12] after $2000 \mathrm{~h}$ in the same conditions. The additive layer thickness was about $5 \mu \mathrm{m}$ thinner than before oxidation. On the contrary, the interdiffusion zone appeared about $5 \mu \mathrm{m}$ thicker $(\sim 70 \mu \mathrm{m})$ after $5000 \mathrm{~h}$ of exposure under atmospheric pressure. Moreover, the Cr segregation at the grain boundaries of the coating area between the interdiffusion zone and the substrate was clearly marked in the X-ray maps (Fig. 4).
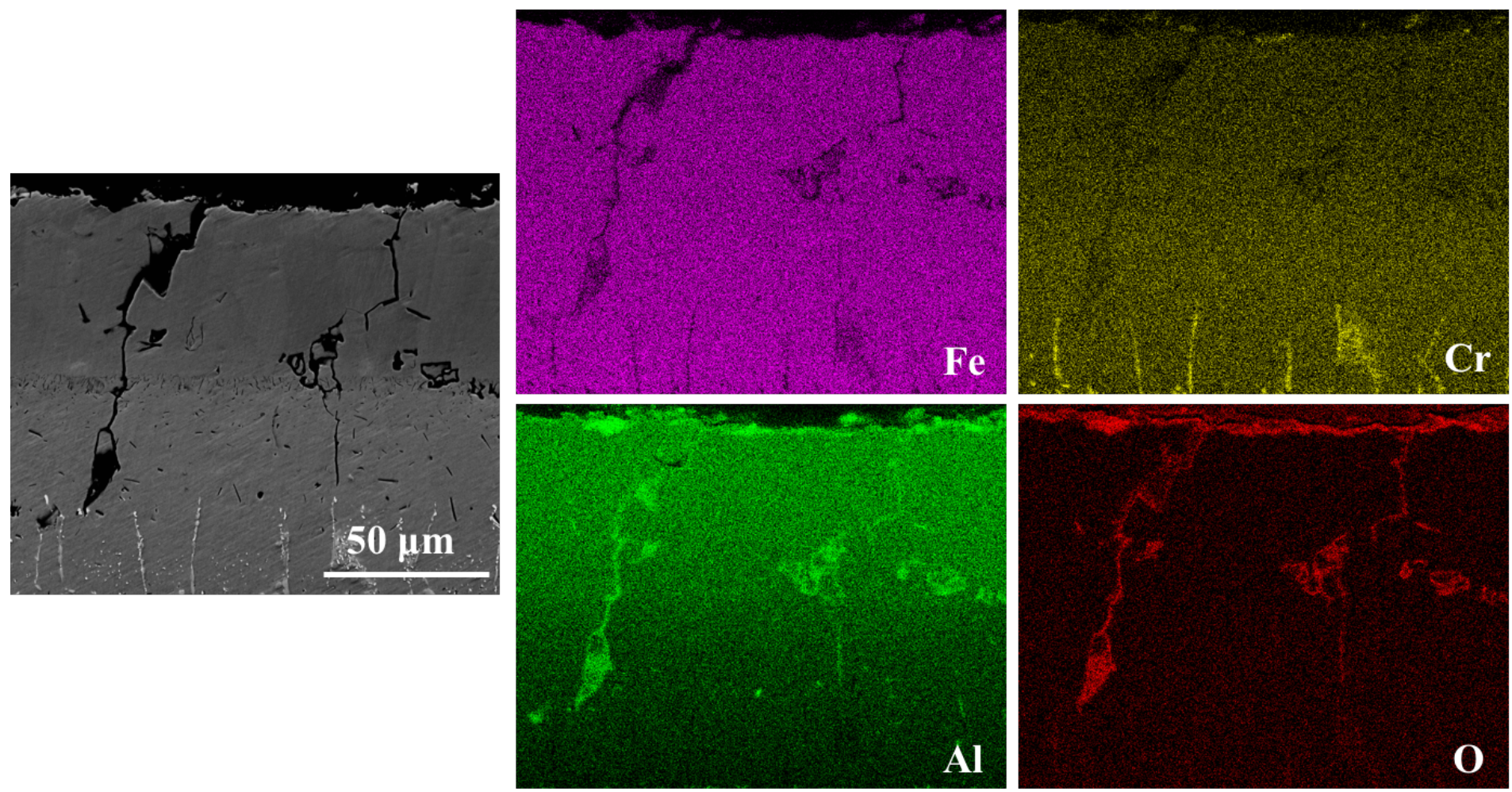

FIGURE 4. X-ray maps of the aluminised P92 ferritic-martensitic steel after 5000 hours in steam, at $650^{\circ} \mathrm{C}$ and under atmospheric pressure.

The Al, Fe and $\mathrm{Cr}$ concentrations revealed by EDS analyses are summarized in Table 2. The Al concentration at the surface of the P92 steels tended to decrease with time, as highlighted in Fig. 5. Consequently, the Fe content followed the opposite trend. At the interface between the additive layer and the interdiffusion zone, the Al content tended to decrease whereas the Fe content increased. On the other hand, the Cr concentration varied very little in view of the uncertainties in all the examined areas. 
TABLE 2. Fe, $\mathrm{Al}$ and $\mathrm{Cr}$ contents $( \pm 1$ at $\%)$ revealed by EDS analyses for the aluminised P92 substrate before and after $2000 \mathrm{~h} \mathrm{[12]} \mathrm{and} 5000 \mathrm{~h}$ in steam at $650^{\circ} \mathrm{C}$ under 1 bar. Illustration of a coated sample and the corresponding areas $\mathrm{n}^{\circ} 1,2$ and 3 .

\begin{tabular}{|l|c|c|c|c|c|c|c|c|c|}
\hline In at\% & \multicolumn{3}{|c|}{ Fe } & \multicolumn{3}{c|}{ Al } & \multicolumn{3}{c|}{ Cr } \\
\hline & 1 & 2 & 3 & 1 & 2 & 3 & 1 & 2 & 3 \\
\hline Aluminised & 54 & 68 & 88 & 40 & 25 & 3 & 4 & 7 & 9 \\
\hline $\mathbf{2 0 0 0 h}$ & 55 & 71 & 89 & 38 & 21 & 2 & 4 & 7 & 9 \\
\hline $\mathbf{5 0 0 0 h}$ & 60 & 72 & 82 & 35 & 22 & 6 & 4 & 7 & 11 \\
\hline
\end{tabular}
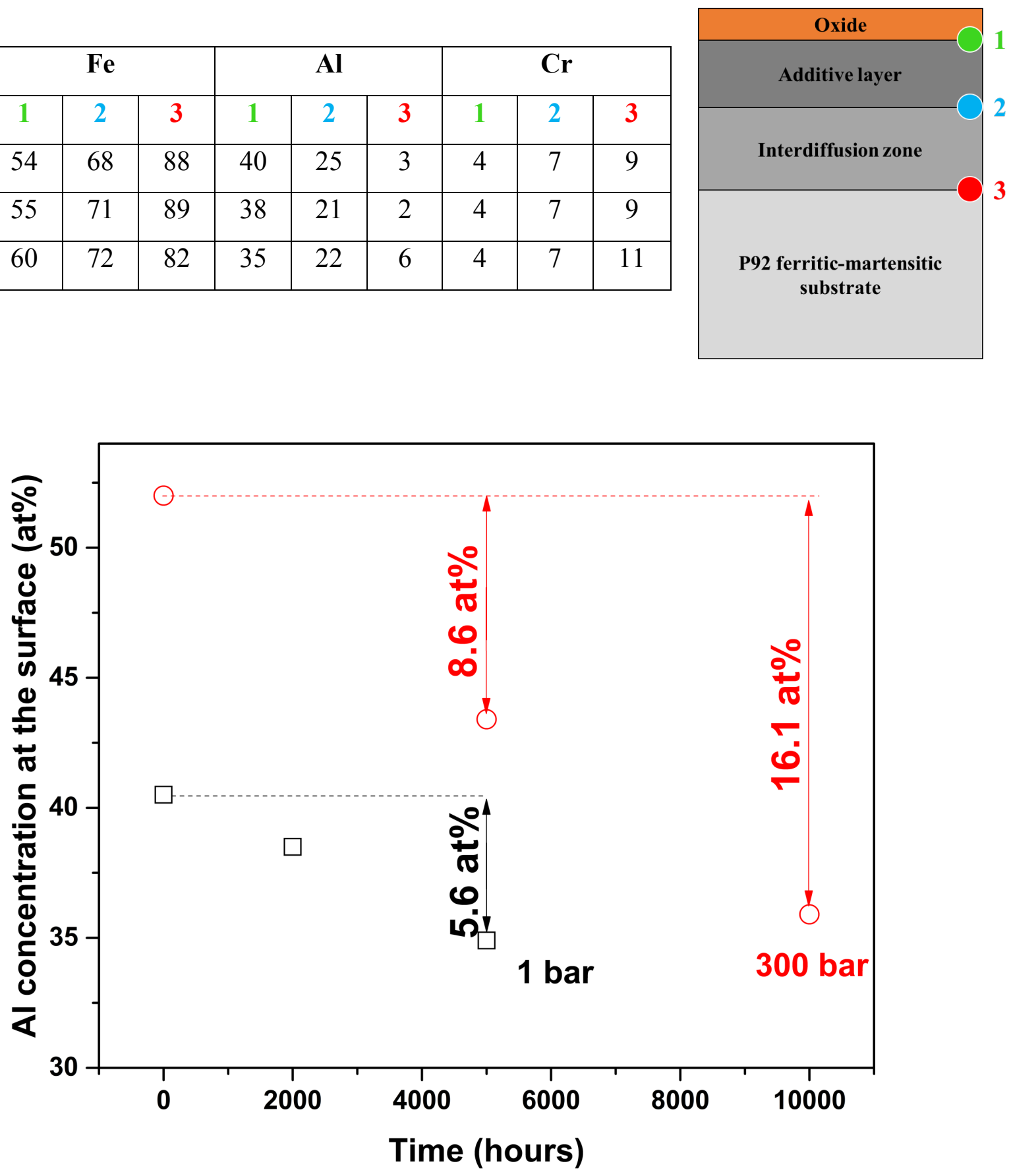

FIGURE 5. Evolution of the $\mathrm{Al}$ content ( $\pm 1 \mathrm{at} \%$ ) at the surface of the coating as a function of time and of pressure. 1 bar (black symboles) vs 300 bar (red symbols). 
The Raman spectra shown in Figs. 6. a. and b. let appear a doublet at $1400 \mathrm{~cm}^{-1}$ which is characteristic of the presence of $\alpha-\mathrm{Al}_{2} \mathrm{O}_{3}[31,32]$ but no signal was observed in the Raman domain (Fig. 6. a.). The XRD analyses (Fig. 6. c.) confirmed these findings with the appearance of the characteristic peaks of the $\alpha-\mathrm{Al}_{2} \mathrm{O}_{3}$ crystal structure. Figs. 6 are in agreement with the results obtained with the X-ray maps shown in Fig. 4.
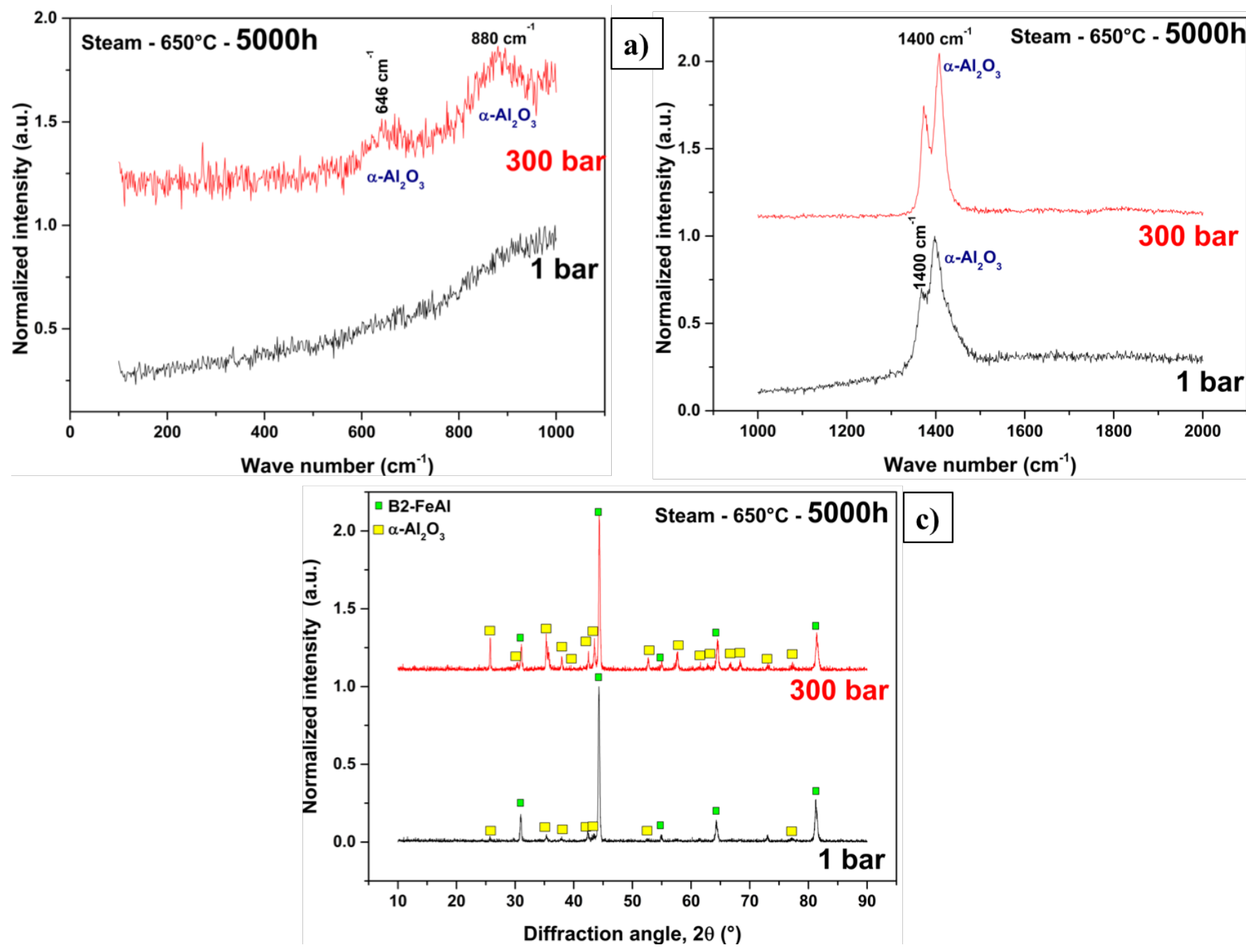

FIGURE 6. Raman spectra ( $a$ and b) and X-ray patterns (c) of aluminised P92 steel after $5000 \mathrm{~h}$ in steam at $650^{\circ} \mathrm{C}$ under 1 (black curves) and 300 bar (red curves).

In order to get closer to the real service conditions in power plants, the pressure was increased to 300 bar. The surface micrographs obtained after $5000 \mathrm{~h}$ in steam, at $650^{\circ} \mathrm{C}$ under high pressure are shown in Fig. 3. c. and d. Compared to those obtained under atmospheric pressure, the oxide morphology was completely different. Indeed, more or less large platelets covered the entire surface of the oxidised samples with additional clusters in some areas. The EDS analyses conducted after $5000 \mathrm{~h}$ under 300 bar are shown in Fig. 7. The elemental 
concentrations appear higher compared to those obtained after aluminisation and after $5000 \mathrm{~h}$ under 1 bar probably dueto some differences on the initial deposited coating thickness that resulted in more Al-rich B2-FeAl coatings ( $52 \mathrm{Al}, 43 \mathrm{Fe}$ and $4 \mathrm{Cr}$, at $\%$ ) at the surface of the asdeposited coatings.

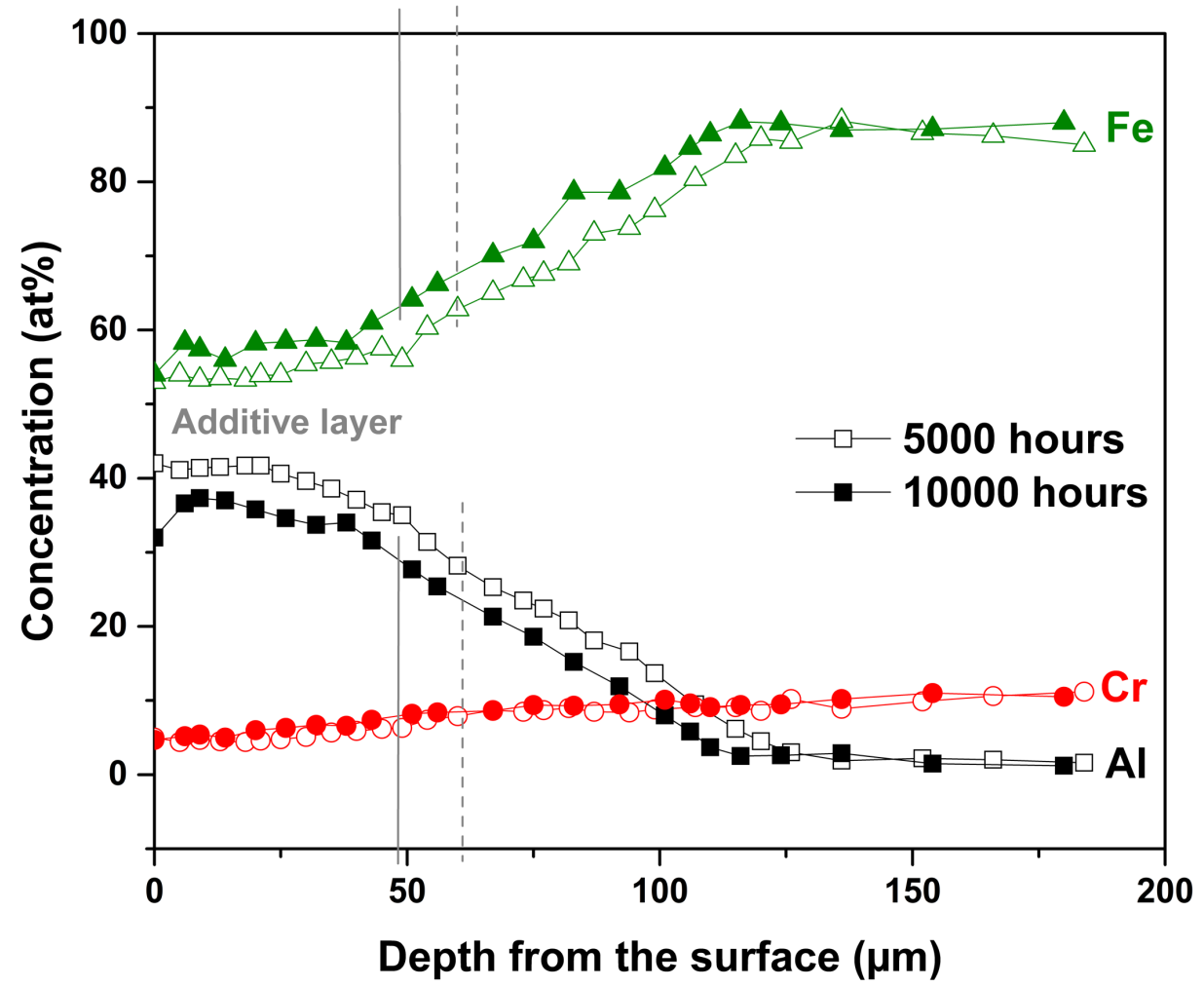

FIGURE 7. EDS profiles of the $\mathrm{P} 92$ steel exposed in steam at $650^{\circ} \mathrm{C}$ and 300 bar for $5000 \mathrm{~h}$ (open symbols) and for $10000 \mathrm{~h}$ (solid symbols).

Compared to the initial concentrations, the $\mathrm{Al}$ content decreased more markedly (about 10 at $\%$ ) with 300 bar than with 1 bar. hConversely, the Fe content increased in the same proportion. The $\mathrm{Cr}$ contents were similar before and after these oxidation tests.

The X-ray maps shown in Fig. 8 highlight the presence of cracks but like with 1 bar, they appeared self-healed. $\mathrm{Al}$ and $\mathrm{O}$ were also detected on the surface of the sample where a thicker oxide scale (compared with Fig. 4) was formed. The oxide formed looked more compact but two layers appeared. Some traces of Fe can be distinguished on the outer part of the oxide layer. Concerning the Raman and XRD analyses (Figs. 6), no signal corresponding to the presence of an iron oxide was detected. Indeed, the Raman analyses showed two additional peaks in the Raman domain (Fig. 6. a.) at 650 and $900 \mathrm{~cm}^{-1}$. Jian et al. [33] have related the first one to the presence of nordstrandite $-\mathrm{Al}(\mathrm{OH})_{3^{-}}$. E. A. Martinez demonstrated that these two peaks are 
characteristic of $\alpha-\mathrm{Al}_{2} \mathrm{O}_{3}$ [34]. The same observations were made by Pedraza et al. upon the oxidation of aluminized IN-800HT in steam at $650^{\circ} \mathrm{C}$ and 1 bar [19].
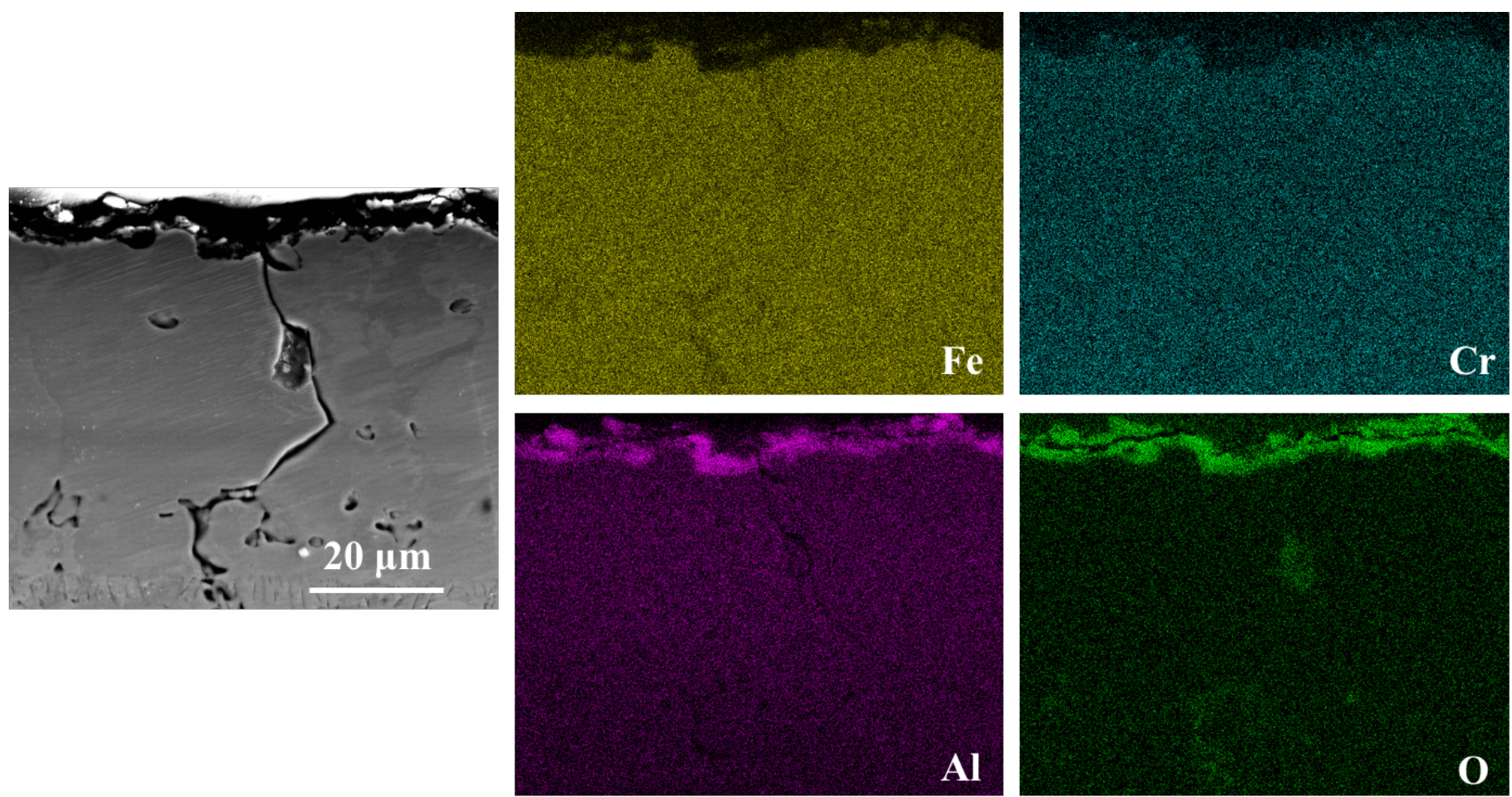

FIGURE 8. X-ray maps of the aluminised P92 ferritic-martensitic steel after 5000 hours in steam, at $650^{\circ} \mathrm{C}$ and under 300 bar of pressure.

After $5000 \mathrm{~h}$ at high pressure, the coating exhibited a thinner additive layer of about $52 \mu \mathrm{m}$ compared to the fresh one $(60 \mu \mathrm{m})$. On the other hand, the interdiffusion zone appeared thicker after the oxidation tests $(72 \mu \mathrm{m})$.

\subsection{Influence of exposure time -300 bar - 5000 and $10000 \mathrm{~h}$ of exposure}

The high pressure steam tests were extended to $10000 \mathrm{~h}$ of exposure. The surface morphology of the oxidised P92 ferritic-martensitic steel is shown in Figs. 9. The platelets were still present and the coverage of the surface was comparable to Fig. 3. c. However, after $10000 \mathrm{~h}$ of exposure, clusters were observed in greater extent and their size was bigger compared to those observed after $5000 \mathrm{~h}$. 

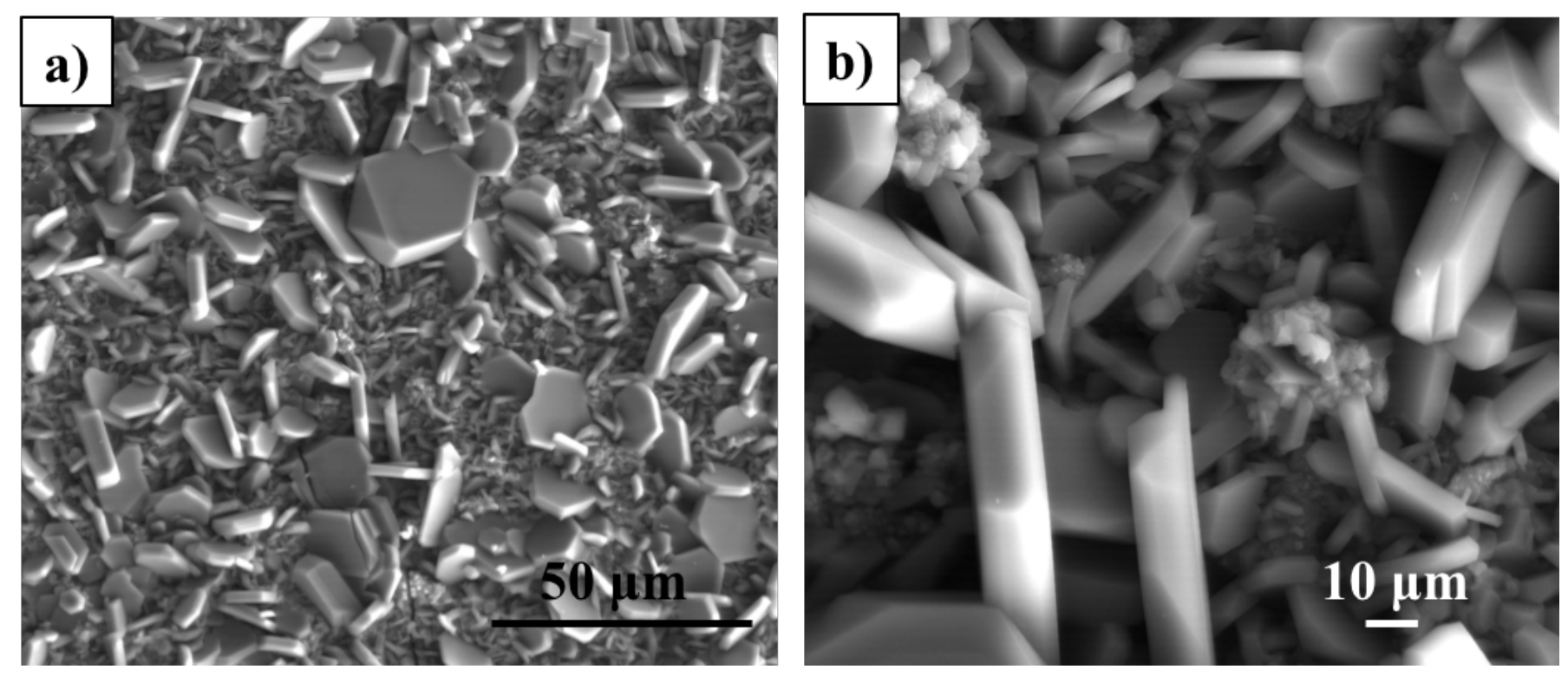

FIGURE 9. Surface images of the aluminised P92 ferritic-martensitic steel after 10000 hours of exposure in steam at $650^{\circ} \mathrm{C}$ and under 300 bar of pressure.

At higher magnification (Fig. 9. b.), it appears that the distribution between the clusters and the platelets is equivalent. The EDS analyses carried out on the platelets highlighted a high amount of $\mathrm{O}(55 \mathrm{O}$ and $43 \mathrm{Al}$, at $\%$ ) whereas on the clusters Fe was detected (20 at $\%$ at least, depending on the analysed areas). Nevertheless, the X-ray maps shown in Fig. 10 were similar compared to those obtained after $5000 \mathrm{~h}$ of exposure. Indeed, a dual oxide layer was still observed and $\mathrm{Al}$ and $\mathrm{O}$ were detected in a large amount in the cracks and on the surface of the oxidised sample. Fe was also observed in some parts of the oxide but in a smaller extent compared to $\mathrm{Al}$ and $\mathrm{O}$. The Raman analyses (Figs. 11. a. b.) let appear two types of signal depending on the analysed area. Indeed, as shown in Fig. 11. a., the spectrum obtained on the platelets was the same compared to that obtained after $5000 \mathrm{~h}$ of exposure under high pressure with the appearance of the $\alpha-\mathrm{Al}_{2} \mathrm{O}_{3}$ peaks. On the contrary, the signal obtained on the clusters had 4 additional peaks corresponding to $\mathrm{Fe}_{2} \mathrm{O}_{3}$ [35-37]. The two peaks corresponding to the $\alpha-\mathrm{Al}_{2} \mathrm{O}_{3}\left(650\right.$ and $900 \mathrm{~cm}^{-}$ ${ }^{1}$ ) were still observed and two less defined peaks were detected around the alumina peak at 650 $\mathrm{cm}^{-1}$. Indeed, signals at 625 and $725 \mathrm{~cm}^{-1}$ were recorded and can be correlated to the presence of iron spinels, as reported in [38].

As regards the coating itself, the $\mathrm{Al}$ concentration decreased at the surface of the additive layer to reach about 39 at\% (Fig. 5). On the other hand, the Fe concentration was about 54 at\% on average on the entire thickness of the diffusion zone. It has been noticed that the variations of $\mathrm{Cr}$ with time were negligible in the additive layer with time. However, the $\mathrm{Cr}$ content evolved 
from 6 at $\%$ (aluminised samples) to 8 at $\%$ after $10000 \mathrm{~h}$ of exposure below the coating/substrate interface. The thickness of the additive layer tended to decrease with time whereas the interdiffusion zone evolved in the opposite trend (48 and $72 \mu \mathrm{m}$, respectively).

Moreover, the cracks still present after aluminisation seemed to propagate to the end of the interdiffusion but without reaching the steel (Fig. 12). Their propagation under high pressure seemed more significantly than under 1 bar. The Al enrichment zone observed below the interdiffusion zone/substrate interface seemed to increase with time. Indeed, after aluminisation this zone was about $33 \mu \mathrm{m}$ whereas after $5000 \mathrm{~h}$ under high pressure it was $44 \mu \mathrm{m}$ and reached $53 \mu \mathrm{m}$ after $10000 \mathrm{~h}$.
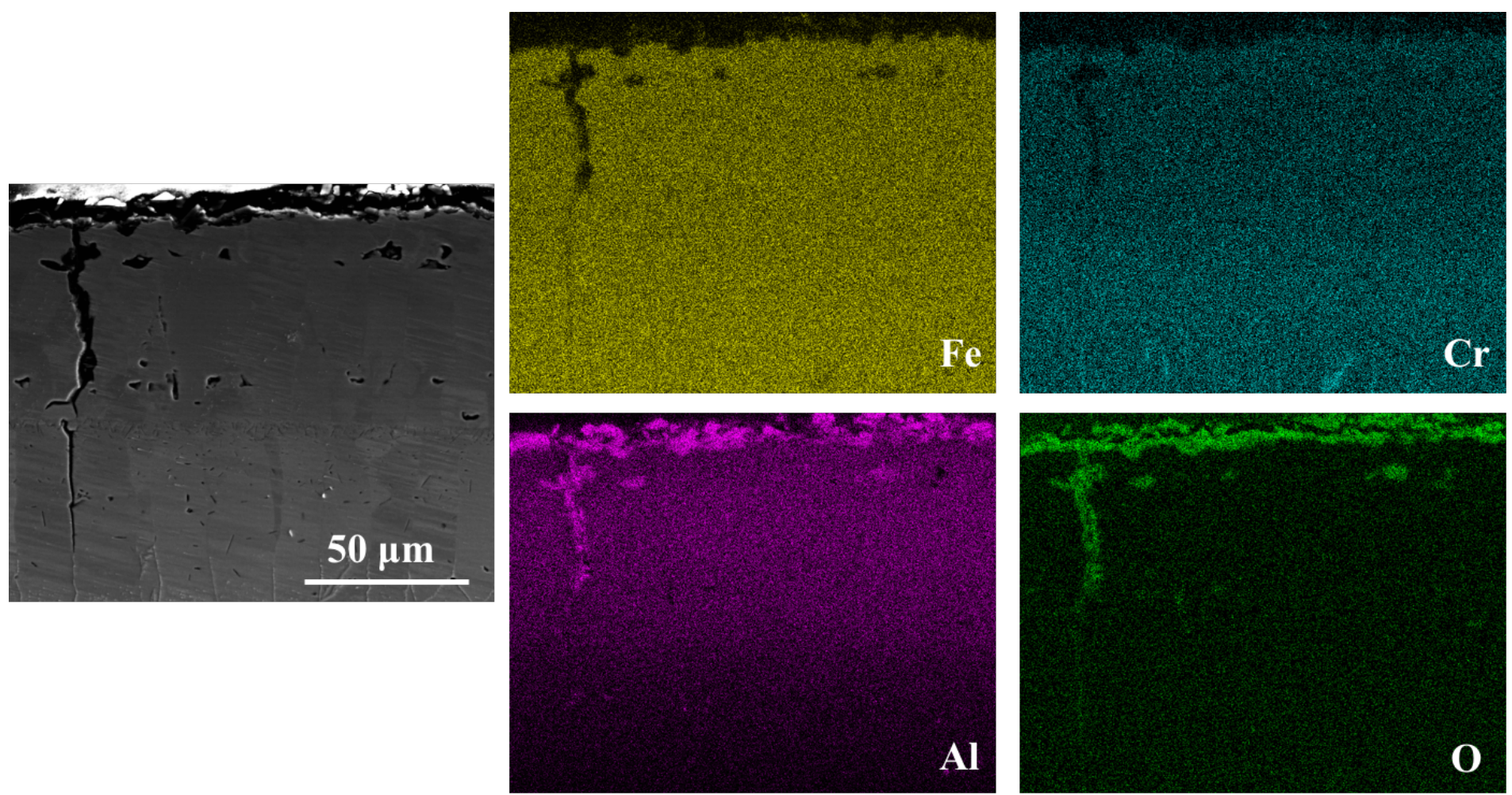

FIGURE 10. X-ray maps of the aluminised $\mathrm{P} 92$ steel exposed for $10000 \mathrm{~h}$ in steam, at $650^{\circ} \mathrm{C}$, under high pressure. 


\section{Platelets}

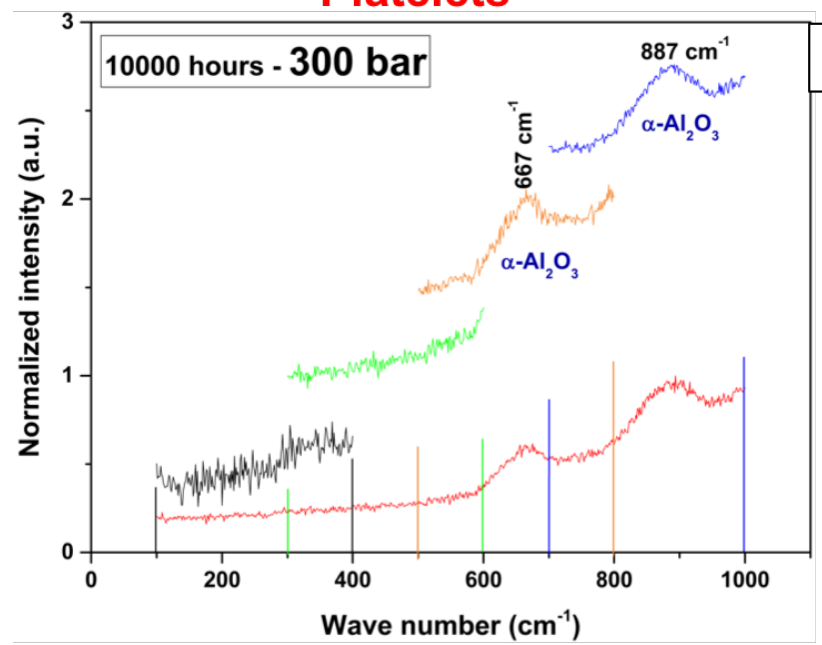

Clusters
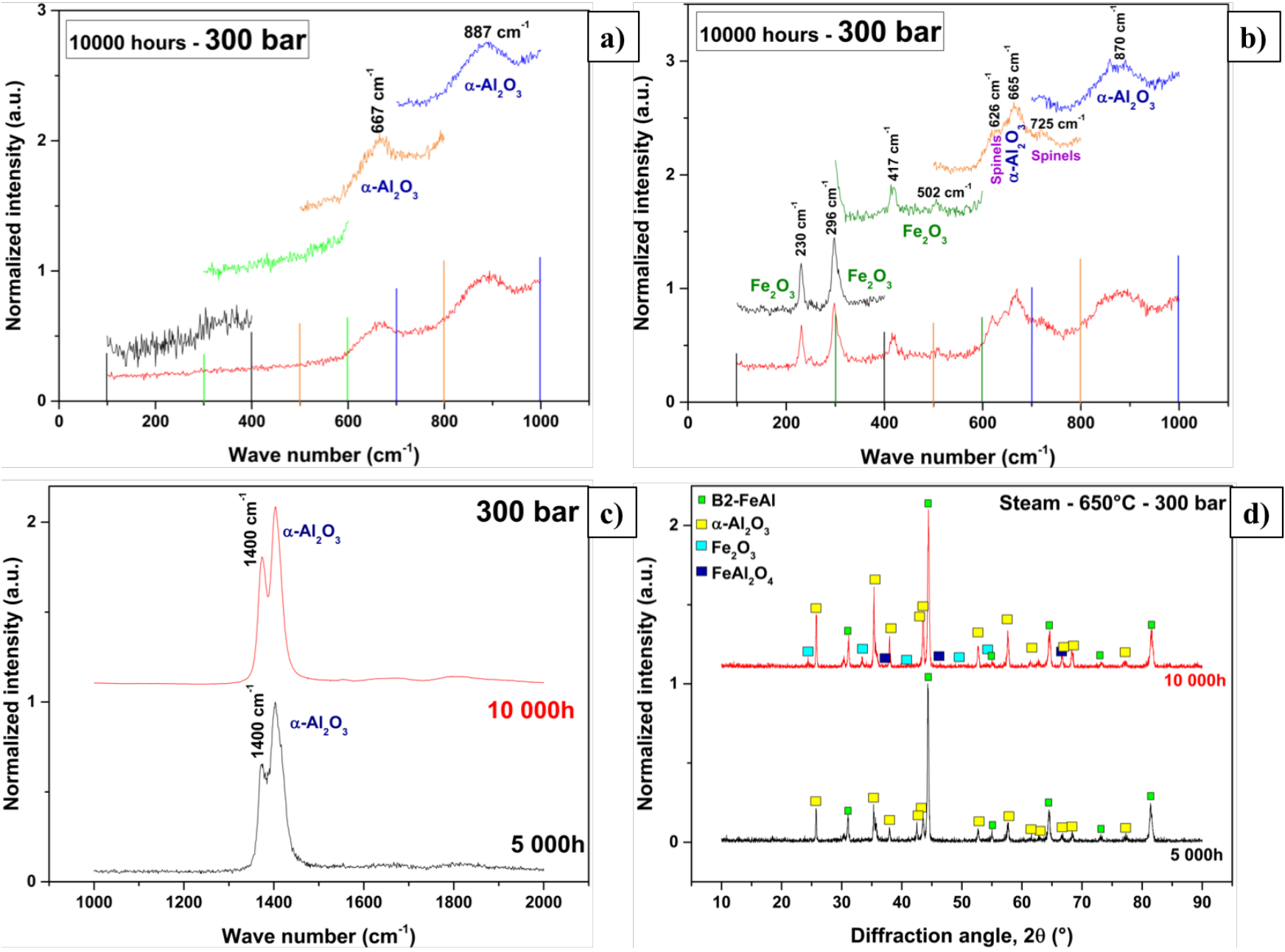

FIGURE 11. (a to c) Raman spectra and (d) X-ray patterns of aluminised P92 steel after 5000 $\mathrm{h}$ (black curves) and $10000 \mathrm{~h}$ (red curves) in steam at $650^{\circ} \mathrm{C}$ and under 300 bar. 

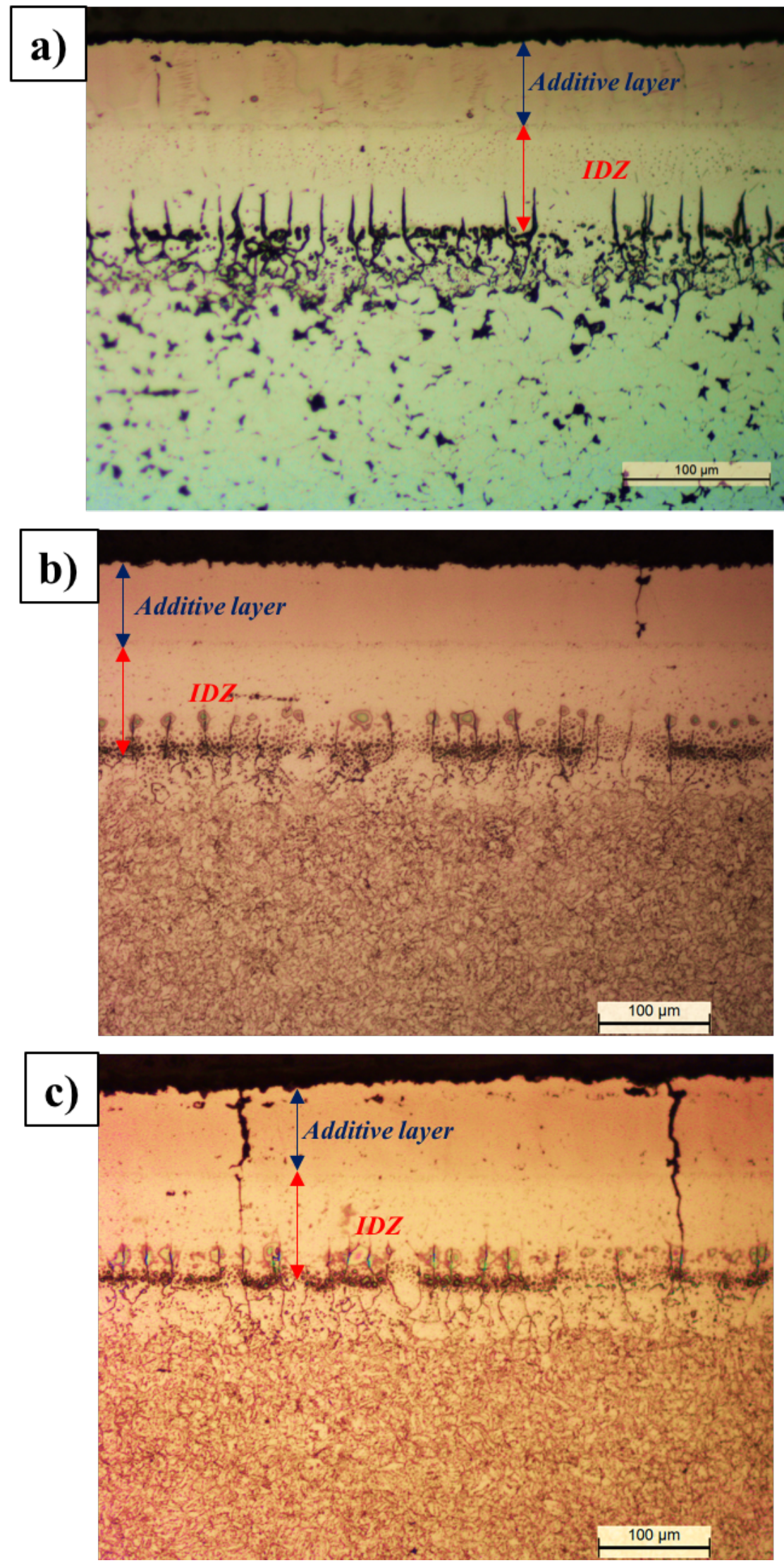

国

FIGURE 12. Optical micrographs of aluminised P92 ferritic-martensitic steel (a) before oxidation tests and after exposure to 300 bar of steam for (b) 5000 and (c) $10000 \mathrm{~h}$. 


\section{DISCUSSION}

\subsection{Aluminised P92 ferritic-martensitic steel}

Aluminium slurry coatings were elaborated on P92 ferritic-martensitic by spraying a waterbased slurry. The following annealing step allowed the simultaneous Al inward diffusion and the Fe outward diffusion $[17,18,20]$, thus resulting in the formation of the B2-FeAl phase. The thermal treatment carried out in this work allowed the formation of shells around the empty $\mathrm{Al}$ microspheres. These shells were oxidised due to the low $\mathrm{O}_{2}$ partial pressure of the annealing gas (Ar), thus oxidising the surface of the coated material $[25,39]$. In these conditions, the aluminised ferritic-martensitic samples appeared to be preoxidised with the appearance of a very thin alumina layer (less than $1 \mu \mathrm{m}$ ) [17]. The coatings elaborated in this study had a good homogeneity but some cracks were detected after the thermal treatment. This phenomenon was correlated in previous studies to the mismatch of the thermal expansion coefficients between the different metallurgical phases [11, 20, 29, 30]. Needle-like AlN nitrides were also detected in the interdiffusion zone of coating due to the presence of nitrogen in the substrate [40]. Moreover, Boulesteix et al. have shown the presence of a $\mathrm{Cr}$ segregation at the interface between the interdiffusion zone and the substrate [20], that can act as a diffusion barrier for the compounds contained in the substrate [41].

\subsection{Influence of a high-pressure steam exposure for 5000 hours of exposure}

Steam tests were performed for $5000 \mathrm{~h}$ at $650^{\circ} \mathrm{C}$ and under atmospheric pressure ( $\left.1 \mathrm{bar}\right)$. The surface of the oxidised samples (Fig. 3. a.) was similar compared to the aluminised one (Fig. 2. a.) with the traces of the light grit blasting carried out after aluminisation. At higher magnification, it is clear that the surface was covered by oxide whiskers as shown in Fig. 3. b. The coating looked similar to the "fresh-ones" in terms of homogeneity but the thickness of the additive layer seemed to decrease from 59 to $54 \mu \mathrm{m}$ after $5000 \mathrm{~h}$ of steam exposure. In contrast, the interdiffusion zone grew thicker. This phenomenon was also reported by Agüero and Muelas after $25000 \mathrm{~h}$ of exposure of $\mathrm{Fe}_{2} \mathrm{Al}_{5}$-based aluminide to 1 bar of steam [40]. Concerning the $\mathrm{Al}$ and Fe content (Table 2$)$, the first one decreased with time ( $5 \mathrm{at} \% \mathrm{Al}$ on the surface of the additive layer), as shown in Fig. 5, whereas the Fe concentration followed the opposite trend (Fig. 6). By comparing with the initial concentrations, it appeared that the Al content was higher at the interface between the coating and the substrate. Bellucci et al. [42] 
and Agüero and Muelas [40] also showed that the Al concentration at the surface of an aluminide coating deposited on different ferritic and ferritic-martensitic steels tended to decrease with time. This phenomenon was directly linked to the Al consumption to form an alumina layer and to Al inward diffusion in the substrate. The X-ray maps (Fig.4) highlighted a distribution of $\mathrm{Al}, \mathrm{Fe}$ and $\mathrm{Cr}$ comparable to the one obtained after aluminisation with $\mathrm{Cr}$ segregating at the grain boundaries of the interdiffusion zone of the coating [20] that may block the interdiffusion of $\mathrm{Al}$ and $\mathrm{Fe}[41]$.

The Raman and XRD analyses (Figs. 6) carried out on the coated P92 ferritic-martensitic steel exposed for $5000 \mathrm{~h}$ in steam at $650^{\circ} \mathrm{C}$ and 1 bar let appear the characteristic signals of the presence of an $\alpha-\mathrm{Al}_{2} \mathrm{O}_{3}$ layer. Moreover, the X-ray maps and the EDS analyses realised on these samples confirmed the high amounts of $\mathrm{Al}$ and $\mathrm{O}$ on the surface of the oxidised samples (Fig. 4). The whisker-like morphology of the oxides shown in Fig. 3. b. demonstrated that the potential transformation from the metastable to the stable alumina occurred [43]. Indeed, previous studies [44-46] have shown that the evolution of the $\gamma-\mathrm{Al}_{2} \mathrm{O}_{3}$ to $\theta-\mathrm{Al}_{2} \mathrm{O}_{3}$ and from $\theta$ $\mathrm{Al}_{2} \mathrm{O}_{3}$ to $\alpha-\mathrm{Al}_{2} \mathrm{O}_{3}$ should take place at higher testing temperatures or for longer exposure time. However, $\alpha-\mathrm{Al}_{2} \mathrm{O}_{3}$ is directly formed upon the coating process prior to oxidation $[16,25]$ and the $\mathrm{Cr}$ contained in the aluminide could play the third element effect, thus sustaining the $\alpha$ $\mathrm{Al}_{2} \mathrm{O}_{3}$ formation $[43,47,48]$. Seraffon et al. have shown that under the same conditions that those used in this work, an aluminised T91 steel was able to form a protective $\mathrm{Al}_{2} \mathrm{O}_{3}$ scale after $5000 \mathrm{~h}$ of exposure. This observation was explained by the Al diffusion within the Al-Fe intermetallic phases. Simultaneously, the Al inward diffusion from the coating to the substrate was observed [49]. The thermal treatment carried out in this study to aluminise the P92 ferriticmartensitic steel allowed the preoxidation of the coated substrate, this probably allowing the faster formation of the stable alumina.

Once the good behaviour of the aluminide coatings checked under atmospheric pressure for $5000 \mathrm{~h}$, the pressure was increased to reach 300 bar. In this case, the oxide morphology was completely different with the appearance of more or less large platelets covering the entire surface of the substrate (Figs. 3. c. d.). The aspect of the as-aluminised surface after grit blasting was not observed anymore after $5000 \mathrm{~h}$ of exposure to $1 \mathrm{bar}$ of steam. The oxide scale appeared more compact compared to the one obtained under 1 bar (Figs. 3. a. b.). Moreover, some small clusters were observed in some parts of the coating (Fig. 3. D). The chemical homogeneity of the coating was basically kept despite the slight decrease of the thickness of the additive layer 
and the corresponding small increase of the thickness of the interdiffusion zone. These evolutions can be correlated to the simultaneous $\mathrm{Al}$ outward diffusion to form and to maintain an oxide scale and to the $\mathrm{Al}$ inward diffusion due to its high coefficient diffusion in $\mathrm{Fe}$ [50]. However, the segregation of $\mathrm{Cr}$ at the grain boundaries of the interdiffusion zone is believed to block any substantial loss of $\mathrm{Al}$ from the coating [41]. The oxide layer formed appeared thicker (Fig. 8) compared to the one obtained with 1 barfor the same time but as with 1 bar, the scale displayed a bilayered structure of oxides mostly composed by $\mathrm{Al}$ and $\mathrm{O}$. Holcomb et al. reported very similar results in uncoated austenitic stainless steel and Ni-based alloys at $670^{\circ} \mathrm{C}$ and 267 bar $[51,52]$. In this study, we have shown that in the thickness of the oxide scale increases with pressure in addition to the changes of scale composition (Fe incorporation) and morphology (platelets and clusters). Muan demonstrated that Fe can be incorporated in alumina scale due to the similar size of $\mathrm{Fe}^{3+}$ and $\mathrm{Al}^{3+}$ cations [53]. Wright et al. reported that the pressure could change the metal cation diffusion in oxides [54] and Otoguro explained that differences between the metallic ions diffusion rates can be created due to the pressure effect [55]. Holcomb also considers that the solid state diffusion within the $\mathrm{Fe}$ and $\mathrm{Cr}$-oxide scales is sufficiently quantifiable but most importantly that the hydrogen injected from steam oxidation increases the oxygen permeability lowering the ability of the alloy to establish a chromia scale and therefore the critical content of chromium to form the chromia scales is also increased [52]. Such reports are very much in line with our observations where Fe incorporated in the scale despite the sufficient amounts of $\mathrm{Al}$ in the coating to maintain a pure $\mathrm{Al}_{2} \mathrm{O}_{3}$ and to explain the changes in morphology of $\mathrm{Al}_{2} \mathrm{O}_{3}$. However, one shall notice that these effects were quite limited as the iron-containing oxide clusters were limited in size and presence and only the local Raman spectra allowed to reveal them at the surface of the scale.

The influence of pressure on the coatings themselves corresponds also to an increase of solid state diffusion that slightly decreases the thickness of the diffusion zone while that of the interdiffusion is increased. However, the force exerted in the opened cracks make them propagate towards the substrate but they heal simultaneously through the formation of aluminium oxides (Fig. 8) also observed in different works either in steam [29, 29] or in air [12].

\subsection{Influence of a high-pressure steam exposure with time}

The high pressure steam tests were finally extended to $10000 \mathrm{~h}$ in order to observe possible changes in the coating or in the oxide scale. As shown in Figs. 9, the oxide morphology obtained 
after $10000 \mathrm{~h}$ of exposure was similar to that obtained after $5000 \mathrm{~h}$ in the same exposure conditions. The thickness of the diffusion zone of the aluminide coatings continued to decrease thus allowing a slight thickness increase of the interdiffusion zone. The Al content revealed at the surface of the additive layer was about 10 at $\%$ lower than that observed after $5000 \mathrm{~h}$ of exposure (Figs. 5 and 7). This is in agreement with the works of Bellucci et al. because of the outward diffusion of Al to maintain the oxide layer which increased with time (Fig. 10) and the subsequent Al inward diffusion [40,42]. The oxide scale continued to grow to reach few additional microns compared to the $5000 \mathrm{~h}$ of exposure. A two-layered structure and the platelets were still observed (Fig. 10) but the proportion of clusters increased (Fig. 9. b.). The EDS analyses carried out on areas of the oxide scale were completely different depending on the analysed areas. Indeed, high amounts of $\mathrm{O}, \mathrm{Al}$ and $\mathrm{Fe}$ were revealed on the clusters (, $56 \mathrm{O}$, $24 \mathrm{Al}$ and $20 \mathrm{Fe}$ on average). However, $55 \mathrm{O}$ and $43 \mathrm{Al}$ (at\%) were observed on the platelets and, therefore, very few amounts of $\mathrm{Fe}(<1.5 \mathrm{at} \%)$. The Raman analyses carried out on reflected such differences in local composition. Indeed, as shown in Fig. 11. a., the spectrum obtained on the platelets was the same compared to that obtained after $5000 \mathrm{~h}$ of exposure under high pressure $\left(\alpha-\mathrm{Al}_{2} \mathrm{O}_{3}\right.$, Fig. 6. a.). In contrast, six additional peaks appeared on the clusters. Four of them at low wave numbers were characteristic of haematite, as previously demonstrated by different authors [35-37]. At higher wave numbers, the $\alpha-\mathrm{Al}_{2} \mathrm{O}_{3}$ signal was still present but the peak at $650 \mathrm{~cm}^{-1}$ was surrounded by two other signals which were associated with the formation of Al-Fe spinels [38]. The EDS analyses carried out on the platelets did not show Cr, thus confirming the Raman and XRD analyses (Figs. 11). Moreover, the characteristic doublet of the stable alumina in the fluorescence domain was found for both oxidation times. The enhanced Fe outward diffusion through the oxide scale $[52,54,55]$ seemed to be confirmed by the appearance of $\mathrm{Fe}_{2} \mathrm{O}_{3}$ and $\mathrm{Fe}$ spinels. Moreover, it has been reported that the pressure involved a higher porosity degree in the oxide scales, thus providing a path of enhanced diffusivity and explaining the pressure effect on the oxidation of the coated P92 ferriticmartensitic steel [56].

In contrast, the was no marked change in the composition of the healed cracks with alumina in spite of their propagation with time at 300 bar did not contribute (Figs. 10 and 12).

\section{CONCLUSIONS}

Steam oxidation tests were performed on slurry aluminium coated P92 ferritic-martensitic steels. 
Firstly, atmospheric pressure tests were carried out for $5000 \mathrm{~h}$. It appeared that a thin oxide scale composed of $\alpha-\mathrm{Al}_{2} \mathrm{O}_{3}$ was formed. The $\mathrm{Al}$ consumption to form the oxide layer coupled with the simultaneous inward diffusion of $\mathrm{Al}$ from the coating to the substrate resulted in some decrease of $\mathrm{Al}$ and of the thickness of the additive layer.

With increasing pressure to 300 bar oxide morphology was completely different compared to that obtained under atmospheric pressure after 5000h of exposure. Under 1 bar, whiskers covered the entire oxidised surface whereas, under 300 bar platelets and some clusters formed at the surface. It appeared that $\alpha-\mathrm{Al}_{2} \mathrm{O}_{3}$ was also formed but some traces of Fe were observed in the clusters. After $10000 \mathrm{~h}$, the same oxide morphology was encountered but the proportion of clusters increased. Therefore, the Fe content contained in the oxide scale increased too in some parts of the oxide. Therefore, the pressure seemed to enhance the outward diffusion of Fe through the oxide scale. $\mathrm{Fe}_{2} \mathrm{O}_{3}$ and $\mathrm{Fe}-\mathrm{Al}$ spinels were revealed by Raman spectroscopy but not by X-ray diffraction.

In addition, the initial tensile cracks of the coatings propagated with increasing pressure and time but healed with $\mathrm{Al}_{2} \mathrm{O}_{3}$. The $\mathrm{Al}$ content revealed at the surface of the coatings at end of the 300 bar pressure tests appeared sufficient to maintain the protective alumina scale.

\section{ACKNOLEDGMENTS}

The authors gratefully acknowledge European Union for the funding of FP7 project "POEMA: Production of Coatings for New Efficient and Clean Coal Power Plant Materials" (Grant agreement no. 310436). The university of Complutense (Madrid) is also acknowledged for their contribution to the steam tests carried out for 5000 hours under 1 bar.

\section{REFERENCES}

1. T.-U. Kern, M. Staubli, B. Scarlin, ISIJ International 42 (2002) 1515

2. J. M. Beér, Progress in Energy and Combustion Science 33 (2007) 107

3. G. R. Holcomb, Ultra-supercritical steam corrosion, $17^{\text {th }}$ Annual Conference on Fossil Energy Materials (2003) DOE/ARC-2003-009 
4. R. Viswanathan, J. F. Henry, J. Tanzosh, G. Stanko, J. Shingledecker, B. Vitalis, R. Purgert, Journal of Materials Engineering and Performance 14(3) (2005) 281

5. A. Agüero, R. Muelas, A. Pastor, S. Osgerby, Surface and Coatings Technology 200 (2005) 1219

6. D. Schmidt, M. C. Galetz, M. Schütze, Surface and Coatings Technology 237 (2013) 23

7. J. C. Vaillant, B. Vandenberghe, B. Hahn, H. Heuser, C. Jochum, International Journal of Pressure Vessels and Piping 85 (2008) 38

8. $\quad$ N-q. Zhang, Z-1. Zhu, H. Xu, X-p. Mao, J. Li, Corrosion Science 103 (2016) 124

9. G. Boissonnet, C. Boulesteix, G. Bonnet, J. Balmain, F. Pedraza, Oxidation of Metals 88 (2017) 191

10. K. Li, H. Ma, Y. He, J. Chang, S-y. Bae, K. Shin, Fusion Engineering and Design (2017) DOI: 10.1016/j.fusengdes.2017.04.133

11. A. Agüero, V. Gonzalez, M. Gutiérrez, R. Knödler, R. Muelas, Materials and Corrosion $62(2011) 561$

12. C. Boulesteix, F. Pedraza, M. Proy, I. Lasanta, T. de Miguel, A. Illana, F. J. Pérez, Oxidation of Metals 87 (2017) 469

13. J. Ehlers, D. J. Young, E. J. Smaardijk, A. K. Tyagi, H. J. Penkalla, L. Singheiser, W. J. Quadakkers, Corrosion Science 48 (2006) 3428

14. Z. Zhu, H. Xu, D. Jiang, X. Mao, N. Zhang, Corrosion Science 113 (2016) 172

15. D. J. Young, B. A. Pint, Oxidation of Metals 66 (2006) 137

16. B. Rannou, F. Velasco, S. Guzman, V. Kolarik, F. Pedraza, Materials Chemistry and Physics 134 (2012) 360

17. F. Pedraza, M. Mollard, B. Rannou, J. Balmain, B. Bouchaud, G. Bonnet, Materials Chemistry and Physics 134 (2012) 700

18. M. C. Galetz, X. Montero, M. Mollard, M. Günthner, F. Pedraza, M. Schütze, Intermetallics 44 (2014) 8

19. F. Pedraza, M. Proy, C. Boulesteix, P. Krukovskyi, M. Metel, Materials and Corrosion 67 (2016) 1059

20. C. Boulesteix, F. Pedraza, "Characterisation of Aluminium Diffusion Coatings Elaborated on Austenitic Stainless Steels and on Ferritic-Martensitic Steels", Article in preparation (2017)

21. F. Pedraza, C. Boulesteix, M. Proy, I. Lasanta, T. de Miguel, A. Illana, F. J. Pérez, Oxidation of Metals 87 (2017) 443 
22. A. Agüero, M. Guttiérrez, V. Gonzalez, Materials at High Temperatures 25 (2008) 257

23. C. Boulesteix, B. Grégoire, F. Pedraza, Surface and Coatings Technology 326 (2017) 224

24. B. S. Mitchell, “An introduction to materials engineering and science for chemical and materials engineers", John Wiley \& Sons Editions, New Jersey (USA) (2004)

25. M. Mollard, $\mathrm{PhD}$ thesis "Elaboration de systèmes barrière thermique par barbotine: comportement du nickel et de ses superalliages revêtus en oxidation cyclique" (in French), Univsersity of La Rochelle (France) (2012)

26. M. Juez-Lorenzo, V. Kolarik, V. Kuchenreuther-Hummel, M. Pötschke, D. Schimanke, $9^{\text {th }}$ International Sumposium of High-Temperature Corrosion and Protection of Materials HTCPM 9, Oxidation of Metals, Les Embiez (France), May 2016

27. X. Montero, I. Demler, V. Kuznetsov, M. C. Galetz, Surface and Coatings Technology 309 (2017) 179

28. ASM Handbook, “Alloy Phase Digrams” Vol. 3 (1992) Ohio (USA)

29. A. Agüero, R. Muelas, M. Gutiérrez, R. Van Vulpen, S. Osgerby, J. P. Banks, Surface and Coatings Technology 201 (2007) 6253

30. A. Agüero, M. Hernandez, A. Santaballa, Oxidation of Metals 79 (2013) 601

31. M. Brossard, B. Bouchaud, F. Pedraza, Materials and Corrosion 65 (2014) 161

32. B. Bouchaud, J. Balmain, G. Bonnet, F. Pedraza, Applied Surface Science 268 (2013) 218

33. Z. Jian, L. Hai-Tao, G. Jun-Hong, H. Fang-Ren, Chinese Physics Letters 32 (2015) 126801-1

34. E. Alija Martinez, $\mathrm{PhD}$ thesis "Analisis de las capas de alumina formadas a elevada temperature sobre aleaciones MCrAlY y barreras térmicas (TBC)" (in Spanish), University of Complutense de Madrid (2010) p. 134

35. J. E. Maslar, W. S. Hurst, W. J. Bowers, J. H. Hendricks, M. I. Aquino, Journal of the Electrochemical Society 147 (2000) 2532

36. T. Miyazawa, T. Terachi, S. Uchida, T. Satoh, T. Tsukada, Y. Satoh, Y. Wada, H. Hosokawa, Journal of Nuclear Science and Technology 43 (2006) 884

37. X. Zhong, X. Wu, E.-H. Han, Corrosion Science 90 (2015) 511

38. H. G. Edwards, J. M. Chalmers, "Raman Spectroscopy in Archaeology and Art History”, Royal Society of Chemistry Editions (2005), Hong Kong (China) p. 147

39. F. Pedraza, R. Podor, Materials Characterization 113 (2016) 198

40. A. Agüero, R. Muelas, Materials Science Forum 461-464 (2004) 957 
41. W. J. Cheng, C. J. Wang, Applied Surface Science 277 (2013) 139

42. A. Bellucci, S. Matera, A. T. Fry, M. Seraffon, EPRI International Conference on Corrosion in Power Plants, San Diego (USA) (2015)

43. G. Di Girolamo, M. Alfano, L. Pagnotta, A. Taurino, J. Zekonyte, R.J.K. Wood, Journal of Materials Engineering Performance 21 (2012) 1989

44. J. Mougin, T. Le Bihan, G. Lucazeau, Journal of Physics and Chemistry of Solids 62 (2001) 553

45. M.W. Brumm, H.J. Grabke, Corrosion Science 33 (1992) 1677

46. M. Mollard, B. Rannou, B. Bouchaud, J. Balmain, G. Bonnet, F. Pedraza, Corrosion Science 66 (2013) 118

47. F. H. Stott, G. C. Wood, and J. Stringer, Oxidation of Metals 8 (1995) 113

48. D. Renusch, M. Grimsditch, I. Koshelev, B. W. Veal, P. Y. Hou, Oxidation of Metals 48 (1997) 471

49. M. Seraffon, A. T. Fry, D. M. Laing, NPL presentation (2014)

50. A. Agüero, M. Gutiérrez, R. Mueals, K. Spiradek-Hahn, “Overview of steam oxidation behaviour of Al protective oxide precursor coatings on P92”, Surface Engineering (2016) 1

51. G. R. Holcomb, $8^{\text {th }}$ International Symposium on Superalloy 718 and Derivates, Pittsburgh (USA) (2014)

52. G. R. Holcomb, Oxidation of Metals 82 (2014) 271

53. A. Muan, Journal of the American Ceramic Society 41 (1998) 275

54. I. G. Wright, R. B. Dooley, International Materials Reviews 55 (2010) 129

55. Y. Otoguro, M. Sakakibara, T. Saito, H. Ito, Y. Inoue, Transactions ISIJ 28 (1998) 761

56. M. G. Angell, S. K. Lister, A. Rudge, $15^{\text {th }}$ International Conference of the Properties of Water and Steam, Berlin (Germany) (2008). 